\title{
sciendo
}

Current Issues in Pharmacy and Medical Sciences

Formerly ANNALES UNIVERSITATIS MARIAE CURIE-SKIODOWSKA, SECTIO DDD, PHARMACIA

\section{Comparison of sensory and rheological properties of green cosmetic creams prepared on different natural, ECOCERT and BDIH certificated self-emulsifying bases}

\author{
Katarzyna Wojciechowska ${ }^{1}$, Adrianna WalczaK ${ }^{2}$, \\ Ewelina Rostowska ${ }^{3}$, Ewa Poleszak ${ }^{1}$ (1)
}

${ }^{1}$ Chair and Department of Applied Pharmacy, Medical University of Lublin, Poland

${ }^{2}$ Student Research Group belonging to Chair and Department of Applied Pharmacy, Medical University of Lublin, Poland

${ }^{3}$ Gabinet Kosmetyczny Claire Beauty, Lublin, Poland

\section{ARTICLE INFO}

Received 21 January 2021

Accepted: 07 December 2021

\section{Keywords:}

cream, emulsifier,

COSMOS,

rheology,

sensory analysis.

\begin{abstract}
The objective of this paper was to evaluate and compare the rheological and sensory properties of six natural cosmetic creams that use ECOCERT certificated emulsifying bases: Beautyderm, Dub Base Expert, Simulgreen ${ }^{\mathrm{mw}} 18-2$, Olivem 1000, Montanov L and Emulgin Succro against two synthetics: Granthix APP and Lanette W.

The use of emulsifying bases in formulas helps to stabilize the product and improve its rheological and sensory attributes. In this study, the physical and chemical properties of several prepared cosmetic creams were determined. Apparent viscosity and thixotropy were evaluated by viscosimeter, while spreadability was ascertained by extensometer. Moreover, a group of 10 trained members evaluated the sensory properties of the formulas. The obtained formulas based upon natural emulsifiers are characterized by very good physical and chemical properties, high stabilization and good usage quality. The results were confirmed by sensory analysis. The cosmetic creams made with synthetic emulsifying bases were rated the worst by the study participants, which correlated with the physical tests.
\end{abstract}

\section{INTRODUCTION}

Production of formulates for body care are one of the fastest developments in the cosmeceutical industry, and it has made great progress in the development and incorporation of new and effective actives in their products. The growing public awareness of what is friendly and beneficial for their skin ensures the popularity of natural and ecological cosmetics.

In order for a product to be considered natural or ecological, it must satisfy certain stringent requirements. Today's cosmetic industry employs many advanced plant components: stable vitamins such as hydrogenated retinol and tetrahexyldecylascorbate [1], together with sophisticated technological developments such as transferosomes, liquid crystals, ethosomes and niosomy [2]. Cosmetics manufacturers try to entice potential customers not only with modern production technology, but also with the composition of cosmetics, which according to customers' expectations, should be based on natural, plant ingredients. However, currently

\footnotetext{
* Corresponding author

e-mail: k.wojciechowska@umlub.pl
}

terms such as natural cosmetics and organic cosmetics are abused by some manufacturers.

Natural cosmetics are associated by the client with something better and healthier for the skin. However, there are no legal requirements that regulate the definition of natural, ecological and organic cosmetics. In the current Regulation of the European Parliament and the Council of Europe $1223 / 2009$, there is only a definition of a cosmetic product, but there is no definition of what a natural cosmetic is and of what requirements it must meet (3). In order to reduce the false naming of cosmetics as eco-cosmetics, representatives of five World and European certification founders; EcoCert Greenlife SAS (France), BDIH (Germany), Soil Association (the UK), Cosmebio (France) and ICEA (Italy) have unified the requirements for labeling products as natural cosmetics. These requirements have been compiled into a standard, which is called the COSMetic Organic Standard - COSMOS. In natural cosmetics, in accordance with the requirements of COSMOS standards, the use of synthetic ingredients may not exceed 5\% (weight/weight). Furthermore, the use of GMOs (genetically modified organisms), 
nanoparticles, plant ingredients extracted with petrochemical solvents and the use of substances such as EDTA (ethylenediaminetetraacetic acid), chlorinated based products, products based on ammoniac and phosphates is prohibited.

The Cosmetic Organic Standard defines precisely when a cosmetic can be considered natural and when it can be considered organic. According to the COSMOS standard, in 'organic cosmetics', the content of certified raw materials may not be less than $10 \%$, in the case of cosmetics labeled only as 'natural content of certified ingredients', this may not be less than 5\% [4,5]. In addition, COSMOS strictly defines the requirements to be met by the water used in the preparation of cosmetics, as well as the processes that are allowed in the preparation of plant raw material, and also determines the type of final packaging of cosmetics [5].

Cosmetic creams are one of the most frequently produced cosmetic formulations. Creams are semi-solid forms with multiphase surface dedicated for use on the outer skin. Physically, they are formed in the processing of thermodynamic, unstable dispersions of immiscible liquids that are stabilized in time owing to a variety of emulsifiers, thickeners and texture components [6]. The use of these substances not only enhances the stability of the product in time, but also allows modifying its sensory and rheological properties.

Cosmetic base cream (blank cream) has a significant influence on the bioavailability of cosmetic agents such as vitamins and plants extract. The degree of hydration of the stratum corneum, as well as its proper lubrication, affect the penetration of active substance into the skin [7].

Emulsifiers play the main role in obtaining stability within cream formulations. Their role is to reduce interphase tension and create uniform compositions [8]. Until recent times, cosmetics producers mainly used single synthetic emulsifiers (ionic or non-ionic) [7] such as Polisorbate 80 $[9,10]$, Span 83 [10], Methyl glucose sesquistearate [11] and Poliacrylate natrium [12]. Applying single emulsifiers to stabilize emulsions usually entails the use of additive emulsifiers, i.e. co-emulsifiers - among others, fatty acids and monoglicerides [7]. In this way, it is possible to adjust appropriate levels of HLB (hydrophilic-lipofilic balance), which will help to obtain a desired type of emulsion [13].

The process of cosmetics production nowadays is largely enhanced with self-emulsifying bases (SEBs). These are ready compositions made of well-matched proportions of emulsifiers, co-emulsifiers and thickeners. Cosmetics prepared with SEBs are characterized by better stability, more beneficial rheological properties and better sensation. Ready-made SEBs have clearly defined HLBs, which definitely facilitates the procedure of creating desired cosmetic formulations. Standardized SEBs also allow for shorter time of component weighing and thus lowers production and storage costs [14].

Based on the overview of available references, one can conclude that there is very little research into the sensory and physical and chemical properties of creams made with natural and synthetic SEBs [15-20]. Krynicka et al. [17] researched the influence of moisturizing creams made with the use of two SEBs: TegoCare 150 (glyceryl stearate, steareth 25, ceteth 20, stearyl alcohol) and Wax Lanette W (sodium lauryl sulphate, cetostearyl alcohol) on the level of skin moisture. In comparative research, TegoCare 150 demonstrated higher value as a substrate in the production of moisturizing creams. Manson D. et al. [21] used SEBs with formulations of cetostearyl alcohol and sorbitan monostearate to create creams of the o/w emulsion type. The final formulation had pseudoplatic behavior with thixotropy properties. The influence of SEB on the stability of creams with sun protection filters was also evaluated in the paper by Gaspar L. and Campas M. [22]. The ionic phosphate base with the cetostearyl alcohol, diacyl phosphate, ceteth 10 - phosphate composition showed better physical stability and higher sun protection factor than did non-ionic base cetearyl alcohol and ceteareth 20 .

In recent times, there has been a lot of interest in natural emulsifiers obtained from olive oil (OLIVEM) [23-28]. Olivem 1000 is a SEB with the formulation: cetearyl olivate and sorbinian olivate. Perfectly matched emulsifiers with the total of HLB 12 in base Olivem 1000 allow the stabilization of o/w emulsions without any other additives. Together with emulsifying properties, Olivem has many other qualities that are crucial in skin care products: it protects the skin from excessive loss of moisture, helps soften the skin and gives perfect spreadability [24,25].

Simulgreen ${ }^{\mathrm{TM}}$ 18-2 (INCI: Hydroxystearyl alcohol and hydroxystearyl glucoside) is a new oil in water emulsifying base. It is made using ingredients of plant origin and in accordance with a process meeting green chemical principles. According to Roso A. et al. [26], creams which contain Simulgreen ${ }^{\text {TM }} 18-2$ as an emulsifier have good sensory analysis without blanching of the skin. The soaping effect is quite often found in cosmetics based on natural emulsifiers. A growing interest in natural cosmetics and the increasingly popular use of self-emulsifying bases in the cosmetic industry have forced the need to analyze and compare the physicochemical and sensory properties of cosmetic formulations.

The objective of this paper was to evaluate and compare rheological and sensory properties of natural, green cosmetic creams using six different natural and ECOCERT certificated self-emulsifying bases against that of two synthetic bases.

\section{MATERIAL AND METHODS}

\section{Cosmetic cream composition and sample preparation}

Eight different samples of cream type oil in water (o/w) were created. Their compositions are presented in Table 1 and differ in the type of self-emulsifying base used (Table 2). The samples were prepared by warming to $80^{\circ} \mathrm{C}$ both phases and then adding the oil phase to the water phase. When the temperatures of the creams fell below $40^{\circ} \mathrm{C}$, heat-sensitive components: squalene, sweet almond oil and vitamin $\mathrm{E}$, as well as the preservative: GFecosafe (dehydroacetic acid and benzyl alcohol) were added and blended together by the use of stirrer IKA Microstar 7.5, at $700 \mathrm{rpm}$.

For the sake of better uniformity, the creams were subsequently homogenised for 2 minutes with the use of a Unquator e/s Gako homogenizer. The creams were then stored in glass containers at $4^{\circ} \mathrm{C}$. The products obtained were given sensory analysis and physicochemical tests complying with current researches [6,29-31]. 
Table 1. Quantitative composition of the creams

\begin{tabular}{|c|c|c|c|}
\hline INCI & Origin & Concern (Supplier) & Content \% \\
\hline \multicolumn{4}{|c|}{ Oil phase } \\
\hline $\begin{array}{l}\text { Self emulsifying } \\
\text { base* }\end{array}$ & & & 5.0 \\
\hline Cetearyl alcohol & $\begin{array}{c}\text { derived from } \\
\text { sustainable palm and } \\
\text { coconut oil }\end{array}$ & LotionCrafter & 3.0 \\
\hline Shea butter crudum & Shea butter & Local supplier & 1.5 \\
\hline Squalene & $\begin{array}{c}\text { vegetable origin from } \\
\text { Olive oil (EcoCert) }\end{array}$ & LotionCrafter & 1.0 \\
\hline $\begin{array}{c}\text { Caprylic/Capric } \\
\text { Triglyceride } \\
\end{array}$ & $\begin{array}{l}\text { vegetable origin from } \\
\text { coconut oil (EcoCert) }\end{array}$ & e-naturalne & 1.5 \\
\hline Sweet Almond Oil & $\begin{array}{c}\begin{array}{c}\text { Prunus Amygdalarus } \\
\text { dulcis oil }\end{array} \\
\end{array}$ & Cortex (gift) & 8.0 \\
\hline \multicolumn{4}{|c|}{ Water phase } \\
\hline $\begin{array}{c}\text { Sodium } \\
\text { pyroglutamate }\end{array}$ & & Cornelius & 1.0 \\
\hline Glycerin & vegetable origin & Local supplier & 4.0 \\
\hline Sodium poliacrylate & & Basf, (gift) & 0.8 \\
\hline Sodium Phytate & $\begin{array}{l}\text { vegetable origin } \\
\text { derived from rice } \\
\text { bran }\end{array}$ & Lotion Crafter & 0.1 \\
\hline Aqua & Aqua destylata & & 72.1 \\
\hline Tocopherol & vegetable orgin & e-naturalne & 1.0 \\
\hline $\begin{array}{c}\text { Dehydroacetic acid, } \\
\text { benzyl alcohol }\end{array}$ & & Acros & 1.0 \\
\hline
\end{tabular}

Table 2. The type and composition of used self - emulsifying base

\begin{tabular}{|c|c|c|c|}
\hline \multicolumn{2}{|c|}{$\begin{array}{l}\text { Trade name } \\
\text { and certifying } \\
\text { organization }\end{array}$} & INCI & Concern \\
\hline 1 & \begin{tabular}{|l|} 
Beautyderm \\
EcoCert
\end{tabular} & \begin{tabular}{|c} 
glyceryl stearate, cetearyl alcohol, stearic \\
acid, sodium lauroyl glutamate
\end{tabular} & Enzym \\
\hline 2 & $\begin{array}{l}\text { Dub Base Expert } \\
\text { (DBE) } \\
\text { EcoCert }\end{array}$ & $\begin{array}{c}\text { glyceryl stearate citrate, sucrose stearate, } \\
\text { polyglyceryl-4 cocoate, cetyl alcohol, } \\
\text { sodium ricinoleate }\end{array}$ & Azelis \\
\hline 3 & \begin{tabular}{|l|} 
Montanov L \\
EcoCert and \\
BDIH \\
\end{tabular} & C 14-22, C 12-20 alkyl glucoside & $\begin{array}{l}\text { Seppic } \\
\text { (gift) }\end{array}$ \\
\hline 4 & $\begin{array}{l}\text { Emulgin Succro } \\
\text { EcoCert }\end{array}$ & Sucrose Polystearate, Cetyl Palmitate & BASF (gift) \\
\hline 5 & $\begin{array}{l}\text { Simulgreen } \\
18-2 \\
\text { EcoCert }\end{array}$ & $\begin{array}{l}\text { Hydroxystearyl alcohol and } \\
\text { hydroxystearyl glucoside }\end{array}$ & $\begin{array}{l}\text { Seppic } \\
\text { (gift) }\end{array}$ \\
\hline 6 & $\begin{array}{l}\text { Olivem } 1000 \\
\text { EcoCert }\end{array}$ & cetearyl olivate, sorbitan olivate & $\begin{array}{c}\text { Local } \\
\text { supplier }\end{array}$ \\
\hline 7 & $\begin{array}{l}\text { Lanette W } \\
\text { Synthetic }\end{array}$ & $\begin{array}{c}\text { Cetearyl alcohol; } \\
\text { Sodium lauryl sulfate }\end{array}$ & BASF \\
\hline 8 & $\begin{array}{l}\text { Granthix APP } \\
\text { (Granthix) } \\
\text { Synthetic }\end{array}$ & $\begin{array}{l}\text { isohexadecane, polyacyloyldimethyl } \\
\text { taurate, polysorbate- } 80\end{array}$ & IMCD (gift) \\
\hline
\end{tabular}

\section{Sensory analysis of the formulations}

The formulations obtained in the tests were analysed by sensory perception: smell, sight, and touch according to Płocica et al. [32]. Sensory analysis was carried out in the Department of Applied Pharmacy, Medical University of Lublin. The research was approved by the Bioethics Committee $\mathrm{nr}$ KE-0254/140/2017. The panel was formed by 10 experienced members (age range between 23-68). Eight sensory

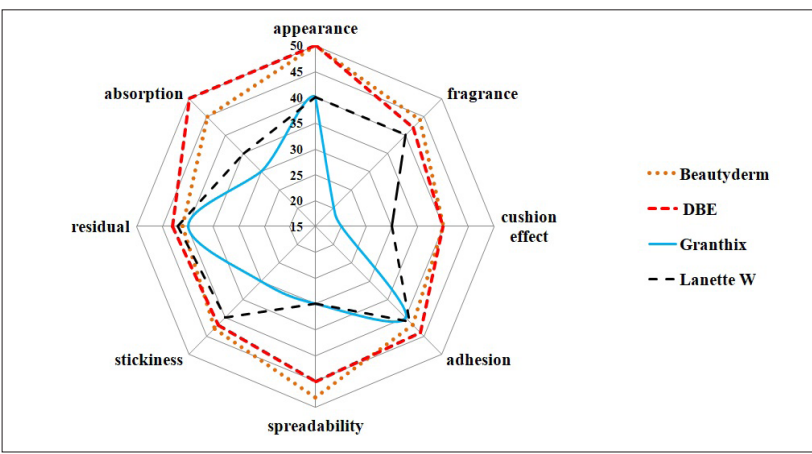

Figure 1. Results sensory analysis of Beautyderm, DBE, Granthix, Lanette W attributes were chosen: appearance, fragrance, cushions effect, adhesion to the finger, spreadability on the back of hand, stickiness of the cream, residual feeling on the skin after absorption, and absorption to the skin. The panellists evaluated the creams on 5-point scale. The experimental methods of the chosen attributes and the obtained effects of the creams are shown in Table 3 . The average results of the analysis are given in Figure 1 and Figure 2.

Table 3. Experimental methods of the chosen attributes and effects of the prepared creams with interpretation by points-based assessment

\begin{tabular}{|c|c|c|}
\hline $\begin{array}{c}\text { Attribute and } \\
\text { definition }\end{array}$ & Method & Interpretation \\
\hline \begin{tabular}{l|} 
Cushion effect \\
Cream is felt \\
between a \\
thumb and a \\
forefinger while \\
rubbing against \\
each other
\end{tabular} & $\begin{array}{l}\text { Apply the } \\
\text { product with the } \\
\text { forefinger then } \\
\text { rub it against } \\
\text { the thumb. } \\
\text { Determine the } \\
\text { perceptible } \\
\text { amount of } \\
\text { cream }\end{array}$ & $\begin{array}{l}5 p-\text { not felt at all } \\
4 p-\text { hardly felt } \\
3 p-\text { not felt very well } \\
2 p-\text { felt } \\
1 p \text { - felt strongly }\end{array}$ \\
\hline \begin{tabular}{|l|} 
Adhesion \\
The cream can \\
be applied on a \\
finger
\end{tabular} & $\begin{array}{l}\text { Apply a small } \\
\text { amount of } \\
\text { cream on a } \\
\text { finger and find } \\
\text { its consistency } \\
\text { and how it } \\
\text { keeps its shape }\end{array}$ & $\begin{array}{l}5 p \text { - easy to apply and keeps its size } \\
\text { well } \\
4 p \text { - fairly easy to apply and keeps its } \\
\text { shape quite well } \\
3 p \text { - difficult to apply and does not keep } \\
\text { its shape } \\
2 p \text { - difficult to apply, it is too thin or } \\
\text { too thick } \\
1 p \text { - product cannot be applied } \\
\end{array}$ \\
\hline $\begin{array}{l}\text { Spreadability } \\
\text { The cream is } \\
\text { easily spread }\end{array}$ & $\begin{array}{l}\text { Apply the } \\
\text { cream on an } \\
\text { inner side of } \\
\text { arm and check } \\
\text { the resistance } \\
\text { during } \\
\text { application }\end{array}$ & $\begin{array}{l}5 p \text { - easy to spread, skin does not react } \\
\text { with resistance } \\
4 p \text { - easy to spread, skin reacts with } \\
\text { minimum resistance } \\
3 p \text { - fairly difficult to spread, skin reacts } \\
\text { with resistance and bleaching effect } \\
2 p \text { - difficult to spread, it is too thin or } \\
\text { too thick } \\
1 p \text { - difficult to spread, skin reacts } \\
\text { with resistance during application or the } \\
\text { product drops off the skin }\end{array}$ \\
\hline \begin{tabular}{|l|} 
Stickiness \\
after \\
application, the \\
cream leaves a \\
sticky layer on \\
the skin
\end{tabular} & $\begin{array}{l}\text { Apply the cream } \\
\text { on an inner } \\
\text { side of arm } \\
\text { and check its } \\
\text { stickiness with } \\
\text { a hand }\end{array}$ & $\begin{array}{l}5 \mathrm{p} \text { - does not leave sticky layer } \\
4 \mathrm{p} \text { - leaves sticky layer, it vanishes very } \\
\text { quickly } \\
3 \mathrm{p} \text { - leaves sticky layer, it vanishes after } \\
5 \text { minutes } \\
2 \mathrm{p} \text { - leaves sticky layer, which is } \\
\text { unpleasant } \\
1 \mathrm{p} \text { - leaves sticky layer, which is } \\
\text { unacceptable }\end{array}$ \\
\hline $\begin{array}{l}\text { Residual } \\
\text { after } \\
\text { application, } \\
\text { cream can } \\
\text { leave greasy } \\
\text { layer }\end{array}$ & $\begin{array}{l}\text { Determine if the } \\
\text { cream leaves a } \\
\text { greasy layer }\end{array}$ & $\begin{array}{l}5 p \text { - leaves a greasy layer which keeps } \\
\text { up to } 30 \text { min } \\
4 p-\text { leaves a greasy layer but it } \\
\text { vanishes with time } \\
3 p-\text { leaves a greasy layer but it } \\
\text { vanishes quickly } \\
2 p \text { - leaves no greasy layer } \\
1 p \text { - product does not leave any layer }\end{array}$ \\
\hline $\begin{array}{l}\text { Absorption } \\
\text { Duration } \\
\text { of cream } \\
\text { absorption into } \\
\text { the skin }\end{array}$ & $\begin{array}{l}\text { Monitor the time } \\
\text { necessary for } \\
\text { the product to } \\
\text { be absorbed into } \\
\text { the skin }\end{array}$ & $\begin{array}{l}5 p-\text { absorbs very well } \\
4 p-\text { absorbs well } \\
3 p-\text { absorbs fairly well, there is a little } \\
\text { bleaching, but it vanishes quickly } \\
2 p-\text {-absorbs badly, there is a bleaching } \\
\text { effect on application, absorption comes } \\
\text { after a few minutes } \\
1 p-\text { absorbs badly or does not absorb } \\
\text { at all }\end{array}$ \\
\hline
\end{tabular}

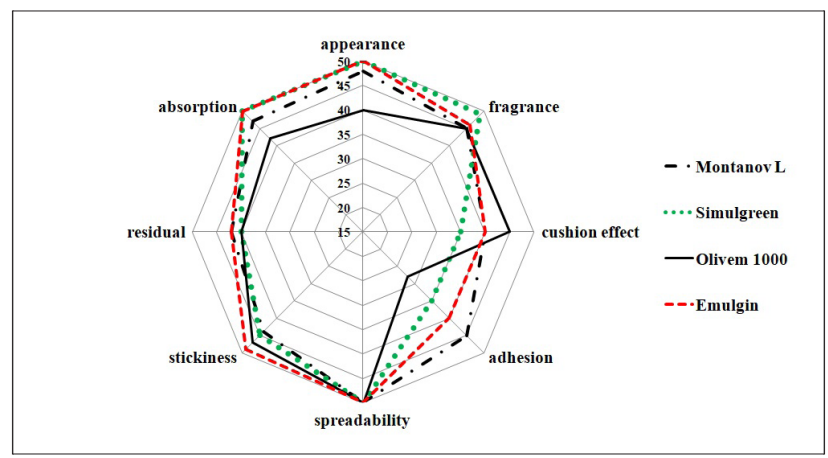

Figure 2. Results sensory analysis of Montanov L, Simulgreen, Olivem 1000, Emulgin 


\section{Physical analysis}

\section{Microscopic analysis}

The analysis was made with optical microscope Leica ICC $50 \mathrm{HD}$, equipped with $40 \times$ optical zoom and the computer program LAS V45. In order to determine the proper type of emulsion, each sample of the cream was stained by methylene blue as indicator and then observed. The size of 300 randomly chosen drops of the dispersion phase was measured and the results with calculated standard deviation are shown in Table 4.

\section{Determination of density}

Density was marked with digital densitometer DMA 500 (Anton Paar, Austria). The $n=3$ results are shown in Table 4.

\section{Determination of $\mathbf{p H}$}

This measurement was undertaken by employing pH meter model CP-411 (Elmetron, Poland), equipped with an indicator electrode, at a temperature of $20^{\circ} \mathrm{C} \pm 2^{\circ} \mathrm{C}$. The sample was introduced into a $100 \mathrm{ml}$ beaker while taking the necessary precautions to fill the container evenly and to eliminate all air bubbles. The measurement was repeated six times. The results of $n=3$ are shown in Table 4 .

Table 4. Summary statement of results: the droplet size of the oil phase, $\mathrm{pH}$, density and spreadability of the preparation calculated as an area under the curves of spreadability (AUC)

\begin{tabular}{|l|c|c|c|c|c|c|c|c|}
\hline \multirow{2}{*}{ Base } & \multicolumn{2}{|c|}{$\begin{array}{c}\text { Droplet size } \\
(\mu \mathrm{m})\end{array}$} & \multicolumn{2}{|c|}{$\mathrm{pH}$} & \multicolumn{2}{c|}{$\begin{array}{c}\text { Density } \\
\left(\mathrm{g} \mathrm{cm}^{-3}\right)\end{array}$} & \multicolumn{2}{c|}{$\begin{array}{c}\text { Spreadability } \\
\text { AUC } \\
\left(\mathrm{g}^{*} \mathrm{~cm}^{2}\right) 103\end{array}$} \\
\cline { 2 - 9 } & & $\pm \mathrm{SD}$ & & $\pm \mathrm{SD}$ & & $\pm \mathrm{SD}$ & & $\pm \mathrm{SD}$ \\
\hline Beautyderm & 10.55 & 2.24 & 5.52 & 0.01 & 0.978 & 0.003 & 21.91 & 0.685 \\
\hline DBE & 8.46 & 2.19 & 5.53 & 0.00 & 0.991 & 0.002 & 21.15 & 0.581 \\
\hline Montanov L & 10.21 & 2.76 & 5.56 & 0.01 & 0.983 & 0.002 & 18.84 & 0.48 \\
\hline Emulgin & 7.82 & 1.49 & 5.60 & 0.01 & 0.956 & 0.005 & 27.65 & 0.076 \\
\hline Simulgreen & 9.78 & 2.05 & 5.55 & 0.01 & 0.986 & 0.003 & 46.18 & 0.643 \\
\hline Olivem 1000 & 9.83 & 2.13 & 5.81 & 0.03 & 0.969 & 0.002 & 32.22 & 0.744 \\
\hline Granthix & 8.57 & 1.68 & 5.75 & 0.03 & 0.998 & 0.001 & 22.96 & 0.850 \\
\hline Lanette W & 11.59 & 2.72 & 5.57 & 0.04 & 0.978 & 0.003 & 22.78 & 0.373 \\
\hline
\end{tabular}

\section{Determination of the spreadability}

The examination of spreadability of the prepared creams was made with an extensometer, at room temperature according to current literature [29,30]. With a syringe, $1 \mathrm{ml}$ of the preparation was placed on the marked circle of the bottom disk, a measuring disk with a scale was attached and then loaded with $200 \mathrm{~g}$ increase of weight every $1 \mathrm{~min}$. Maximum load was $1400 \mathrm{~g}$. In order to analyse spreadability of the preparation, the areas below the spreadability curves AUC [j.u.] were calculated and then compared. The results of these measurements are shown in Table 4.

\section{Rheological study}

Rheological study is an essential part of quality control. Rheological parameters such as flow behaviour, apparent viscosity, yield point and thixotropy can make it easier to predict the reaction of the product during preparation, packaging and finally application on the skin. Rheological measurements were carried out $24 \mathrm{~h}$ after preparation. A Rheolab QC (Anton Paar, Austria) rotational rheometer with coaxial cylinders CC27 was used for the determination of the relation between shear stress and shear rate. Flow curves were ascertained at shear rate range from $0,1 \mathrm{~s}^{-1}-300 \mathrm{~s}^{-1}$ at constant temperature $20^{\circ} \mathrm{C}$ by the use of Peltier (Anton Paar, Austria). Prior to measurements, each sample was tempered for $240 \mathrm{~s}$, and the time span was set to $5 \mathrm{~min}$, during which, shear rate increased from 0,1-300 $\mathrm{s}^{-1}$ and reverse measurements down to $0,1 \mathrm{~s}^{-1}$ took additional 5 mins. RheoCompass ${ }^{\mathrm{TM}}$ software version 1.19 was used to obtain flow properties parameters and thixotropy. Using regression analysis, the parameters of the power law model, Herschel-Bulkley model and Casson model were calculated. For the analysis, we chose the model with the highest regression coefficient $\mathrm{R}^{2}$. All results are summarized in Table 5. Examples of flow curve with power law model for the three self-emulsifying bases are presented in Figure 3 and Figure 4.

Table 5. Parameters of the Power Law model

\begin{tabular}{|l|c|c|c|c|c|}
\hline \multicolumn{1}{|c|}{ Base } & $\begin{array}{c}\mathrm{K} \\
{[\mathrm{Pasn}]}\end{array}$ & $\begin{array}{c}\mathrm{n} \\
{[-]}\end{array}$ & $\mathrm{R}^{2}$ & $\begin{array}{c}\mathrm{\eta}_{\mathrm{a}}\left(10 \mathrm{~s}^{-1}\right) \\
{[\mathrm{mPas}]}\end{array}$ & $\begin{array}{c}\mathrm{AUC} \\
{\left[\mathrm{Pas}^{-1}\right]}\end{array}$ \\
\hline Beautyderm & 71.81 & 0.276 & 0.994 & 14439 & 3501 \\
\hline DBE & 152.70 & 0.226 & 0.996 & 27034 & 8336 \\
\hline Montanov L & 122.53 & 0.250 & 0.980 & 25375 & 6567 \\
\hline Emulgin & 123.6 & 0.261 & 0.980 & 22660 & 5101 \\
\hline Simulgreen & 32.14 & 0.368 & 0.998 & 8599 & 4396 \\
\hline Olivem 1000 & 25.01 & 0.170 & 0.984 & 3743 & 2116 \\
\hline Granthix & 204.26 & 0.217 & 0.981 & 37976 & 11079 \\
\hline Lanette W & 127.50 & 0.216 & 0.982 & 23463 & 9203 \\
\hline
\end{tabular}

apparent viscosity $-\eta_{\mathrm{a}}$ calculated at shear rate $10 \mathrm{~s}^{-1}$ and hysteresis loop area AUC

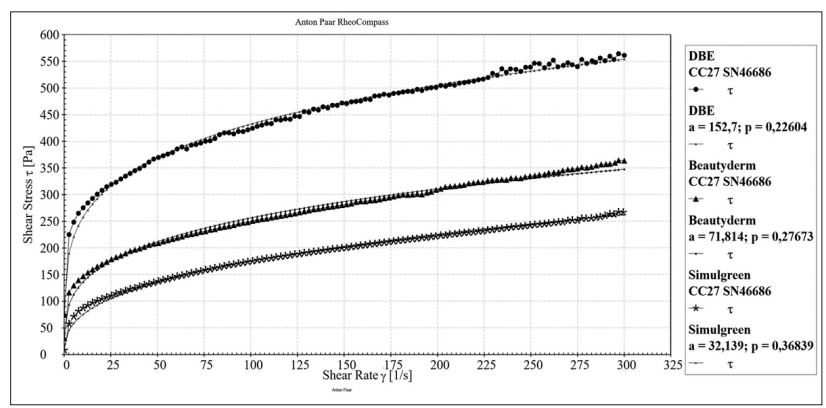

Figure 3. Flow curves of the samples with different self-emulsifying base according to Ostwald de Waele's-Power Law model

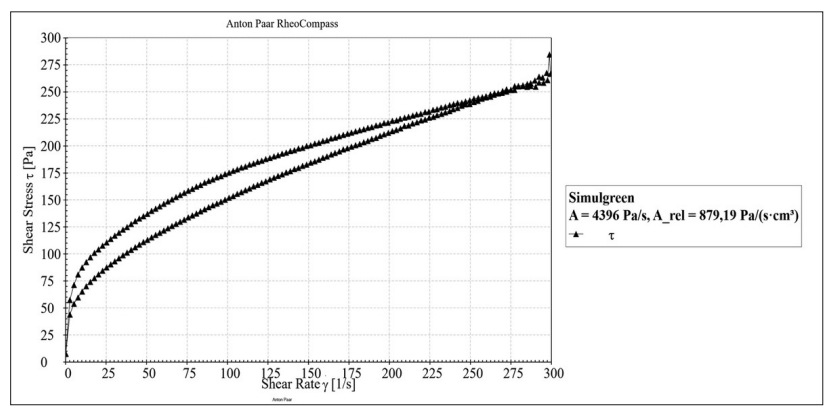

Figure 4. Example of ascending and descending flow curves with closed hysteresis loop area of cream - made with Simulgreen base 


\section{RESULTS}

\section{Sensory analysis}

All except Granthix-based formulations were snow-white in colour and had pleasant scents typical of unrefined shea butter. The aforementioned had an unpleasant, chemical smell. All the preparations had a fine and homogenous textures, as well as smooth shiny surfaces without lumps and air bubbles. In sensory analysis, all creams had excellent performance. They applied easily and kept their shape. Creams based on Olivem 1000, however, failed to keep their shape on being applied on a finger. All the formulations were easily felt while rubbing against fingers. The preparations spread well on the forearm and absorbed quickly. The creams prepared on bases: Granthix and Lanette W showed slight bleaching effect while being rubbed into the skin, but they absorbed quickly. All the preparations left a characteristic light and greasy layer on the skin. The results of the sensory analysis of the preparations are typical of normal skin caring creams.

The study of physical characteristics of the formulations proved that the preparations were type w/o emulsions, the size of the balls in the oil phase ranged from approx. 7,82 $\mu \mathrm{m}$ for the Emulgin base, to $11,59 \mu \mathrm{m}$ for the Lanette $\mathrm{W}$ base. The density of each preparation was very similar; practically the same. The determination of $\mathrm{pH}$ allowed for a comparison to physiological $\mathrm{pH}$ value of the skin. In the analysis, the $\mathrm{pH}$ values of the preparations were slightly acid.

\section{Rheological study}

Rheological study of the preparations involved the evaluation of viscosity, thixotropy and spreadability. Recognizing rheological parameters gives important information as it helps to predict the reaction of the formulation not only in processing, but also in later use [20]. The experiments were conducted at $20^{\circ} \mathrm{C}$ and allowed to the drawing of flow curve shear stress $[\mathrm{Pa}]$ versus shear rate $\left[\mathrm{s}^{-1}\right]$. The analysis confirmed that samples of the creams are pseudoplastic fluids with shear thinning behaviour. Ostwald de Waele's model (Best Power Law model) $\left(\mathrm{Tr}=\mathrm{k} \mathrm{Dr}^{\mathrm{n}}\right)$ was used to determine consistency parameter, $\mathrm{K}-\left[\mathrm{Pas}^{\mathrm{n}}\right]$, flow index $-\mathrm{n}[-]$. Apparent viscosity $\eta_{\mathrm{a}}$ was calculated at shear rate $10 \mathrm{~s}^{-1}$. Note: Soriano Jimmenez M.M. (20), in his research on moisturizing properties of the cream with base NEO PLC, obtained a flow curve that he described with the power equation $\operatorname{Tr}=55.53 \mathrm{Dr}^{0} .524$. The flow type in accordance with Ostwald de Waele's model is typical of light creams [7,20,33]. Cosmetic creams described by Moravkova T. and Filip P [33] also followed Ostwald de Waele's model. Depending on the emulsifier used (Arlacel 989, Arlatone T), the values of viscosity coefficient and flow index were: $(\mathrm{k}=28,12, \mathrm{n}=0,46),(\mathrm{k}=13.90, \mathrm{n}=0.52)$, respectively. Very low values of apparent viscosity at Dr$10.0 \mathrm{~s}^{-1}$ were obtained only for the cream with base Olivem 1000 (3743 mPas), which gives rise to the suspicion that with its prescribed composition, it is much better for body balms $[8,33,34]$. At shear rate $10 \mathrm{~s}^{-1}$, the other preparations had viscosity comparable to the research data $[20,35]$. The analyses conducted at ascending and then descending shear rate helped to obtain at a temperature of $20^{\circ} \mathrm{C}$, a closed histeresis loop area on all the preparation rheograms. Creams prepared with Granthix and Lanette N showed high thixotropy, which coincide with the results of sensory analysis. All probants was evaluated as difficult to spread and absorb into the skin. The value of thixotropy for the other creams is comparable to the research data [20], which confirms the researchers' opinion that the formulations will be easy to spread on and absorb into the skin.

A supplementary examination that completes the rheological study of the cosmetic preparations is an extensibility test under the action of applied load [20]. The analysis of areas under curves AUC [j.u.] enabled a comparison of the preparations that is presented in Table 4. The highest level of extensibility was noticed in the cream prepared with Simulgreen base and Olivem 1000, which is in connection with their low structural viscosity. Extensibility of the other preparations was similar, which might suggest that their spreadability on the skin will be high.

\section{DISCUSSION}

The growing interest in natural cosmetics has prompted manufacturers to look for organic ingredients that meet the requirements of COSMOS, such as eco-emulsifiers, ecooils, eco-butter. Cosmetics containing natural and certified vegetable ingredients or products obtained from animals, such as honey, are more friendly to our skin than cosmetics containing synthetic products or petroleum derivatives. However, it is not only the safety of cosmetics that is crucial for manufacturers. In order for the product to appeal to the consumer, it must also have a nice appearance, a pleasant smell and have very good skin spreadability. Cosmetic consistency, together with its scent and appearance, is important in consumer choice. Without emulsifiers and other stabilizing components, creams cannot have perfect quality and texture. Using natural or synthetic emulsifying bases that are prepared from especially composed mixture of emulsifiers, co-emulsifiers and stabilizing components is advantageous for manufacturers, as it enables a shorter time of weighing the components, minimizes storing costs and, at the same time, helps to prepare a product that is stable in time. The choice of emulsifying bases has a crucial influence on the production of stable cosmetic creams with favourable utility.

The cosmetic creams obtained in this study, for the preparation of which self-emulsifying bases of various natural origin were used, had similar sensory and physicochemical properties. None of the creams significantly differed in terms of their properties. Creams made with synthetic bases were, however, noted by the testers to be slightly worse, due to the chemical smell and weaker absorption into the skin.

Among the creams prepared with the use of natural, certified emulsifiers, all creams were rated very positively by the testers. However, the cream with Simulgreen was rated the best.

\section{CONCLUSION}

1. Creams made with the use of natural emulsifying bases had very good physicochemical properties; that is, they 
spread very well over the skin, were quickly absorb into the skin, and did so without superficial whitening effect.

2. Creams made of natural emulsifying bases had lower thixotropy values, thanks to which they spread better on the skin and absorbed into it faster.

3. Creams made with the use of natural self-emulsifying bases were accepted by probants better than creams made of synthetic emulsifiers.

4. Sensory evaluation of cosmetic preparations allows completing the physicochemical tests.

\section{ACKNOWLEDGEMENTS}

The authors are grateful to BASF, Seppic, Cortex and IMCD for providing free samples of substances.

The authors are grateful to the panellists for their participation.

The author declares no conflict of interests.

\section{ORCID iDs}

Katarzyna Wojciechowska

(Dhttps://orcid.org/0000-0001-9496-2929

Ewa Poleszak (1Dhttps://orcid.org/0000-0003-4359-3953

\section{REFERNCES}

1. Draelos ZD. Cosmeceuticals. Procedures in cosmetic dermatology. Elsevier; 2015.

2. Kim B, Cho H-E, Moon SH, Ahn H-J, Bae S, Cho H-D, et al. Transdermal delivery systems in cosmetics. Biomed Derm. 2020; $4(10)$.

3. Regulation (EC) No $1223 / 2009$ of the Eurapean Parliament and of the Council of 30 November 2009 on cosmetic products. Official Journal of the European Union; 22.12.2009. [https://ec.europa.eu/health/ sites/health/files/endocrine_disruptors/docs/cosmetic_1223_2009_ regulation_en.pdf] (access: December 2020).

4. ECOCERT - standard for natural and organic cosmetics, Version 3.1; June 2020. [https://a7e08fa4-7e84-472f-86dd-95a19f777744.filesusr. com/ugd/0bbe4a_7af6a7f98e7f4a21a429ea27863d0da5.pdf] (access: December 2020).

5. COSMOS - standard technical quide, Version 3.1; June 2020. [https:// a7e08fa4-7e84-472f-86dd-95a19f777744.filesusr.com/ugd/0bbe4a ac00d81b94954617a68e9e065f260e93.pdf] (access: December 2020).

6. Hiroshi I, Kunio S. Ingredients and production of cosmetics. Technology of skin and hair care products in Japan. Springer; 2013.

7. Moravkova T, Filip P. The influence of thickeners on the rheological and sensory properties of cosmetic lotions. Acta Polytechnica Hungarica. 2014;11:173-86.

8. Eccleston GM. Function of mixed emulsifiers and emulsifying waxes in dermatological lotions and creams. Colloid Surf A. 1997;1:123-4, 169-82.

9. Gallardo V, Muñoz M, Ruíz M. Formulations of hydrogels and lipogels with vitamin E. J Cosm Derm. 2015;4:187-92 .

10. Jiao J, Burgess DJ. Rheology and stability of water-in-oil-in-water multiple emulsions containing span 83 and tween 80. AAPS Pharm Sci. 2003;5:62-73.

11. Touzan P, DeLambre P. Cosmetic and/or dermatological composition containing salicyclic acid derivative and its use. US patent 6281203 B1 1999.

12. Medina-Torres L, Calderas F, Sanchez-Olivares G, NuñezRamirez DM. Rheology of sodium polyacrylate as an emulsifier employed in cosmetic emulsions. Ind Eng Chem Res. 2014;53: 18346-51.

13. Shahin M, Hady SA, Hammad M, Mortada N. Development of stable o/w emulsions of three different oils. Int J Pharm Stud Res. 2011;2:45-51.
14. Tharwat, FT. Emulsion, formation, stability and rheology. [https:// www.wiley-vch.de/books/sample/3527319913_c01.pdf] (access: December 2020).

15. Flemming E, Hehner U, Wilhelm E, Eicken U, Jungo S, Kischka $\mathrm{KH}$, et al. Cosmetic care product with two components. US patent 6117436 A, 2000.

16. Gao LQ, Shu WJ, Gao Y, Zhang JJ. Optimization of amorolfine self-emulsifying base cream by d-optimal mixture design and its rheology. Cent South Pharm. 2010;7.

17. Krynicka I, Żebrowska-Szulc A, Sieradzki E. The influence of emulsifying waxes and moisturizing factors of face creams on the level of skin moisture. Farm Pol. 2011;67:3-8.

18. Martin BJ, Birch RA, Tuck KM. Self-emulsifying encapsulation material. US patent 5711941 A, 1998.

19. Sikora E. Cosmetic emulsions. Crakow: Coracow University of Technology; 2019.

20. Soriano Jiménez MM, Fresno Contreras M, Sellés-Flores E. Development of a cream from a self-emulsifying base and moisturizing actives. Il Farmaco. 2001;56:513-22.

21. Masson DS, Morais GG, Morais JM, Andrade FF, Santos OD, Oliveira WP, et al. Polyhydroxyalcohols and peach oil addition influence on liquid crystal formation and rheological behavior of o/w emulsions. J Disper Sci Technol. 2005;26:463-8.

22. Gaspar LR, Campos M. Rheological behavior and the SPF of sunscreens. Int J Pharm. 2003;250(1):35-44.

23. Gallardo V, Muñoz M. Formulations of hydrogels and lipogels with vitamin E. J Cosm Dermatol. 2015;4:187-92.

24. Goncharova AA, Baranova I. The study of the influence of a-lipoic acid, urea and tea tree oil on the rheological properties of the emulsion cream vehicle for use in diabetic foot syndrome. J Chem Pharm Res. 2014;6:429-35.

25. Maisuthisakul P, Harnsilawat T. Characterization and stabilization of the extract from mango seed kernel in a cosmetic emulsion. Kasetsart J Nat Sci. 2011;45:521-9.

26. Roso A, Clemenceau F, Guilbot J, Kerverd S. Simulgreen ${ }^{\text {sx }} 18-2$ : a new green based o/w emulsifying structure for concentrated performances. Cosm Sci Tech. 2012.

27. Martínez MA, Ruíz-Muñoz de Benavides M, Gallardo LV. Influence of the concentration of a gelling agent and the type of surfactant on the rheological characteristics of oleogels. Il Farmaco. 2003;58:1289-94.

28. Osborne R, Carver RS, Mullins LA, Finlay DR. Practical application of cellular bioenergetics to the care of aged skin. Br J Dermatol. 2013;169:32-8.

29. Samczewska G, Ciałkowska-Rysz A. The comparative studies on the bioavailability of morphine hydrochloride and morphine sulphate in model ointments and hydrogels. Pol Med Paliatywna. 2006;5(3):94-107.

30. Garg A, Aggarwal D, S Garg, Singla AK. Spreading of semisolids formulation. An update. Pharm Tech. 2002;9:84-105.

31. Moulai-Mostefa N, Hadji-Sadok A, Sabri N, Hadji A. Determination of optimal cream formulation from long term stability investigation using a surface response modeling. Int J Cosm Sci. 2006;28:211-8.

32. Płocica J, Tal-Figiel B, Figiel W. Rheological and sensory tests used to evaluate cosmetic preparations. Świat Przem Kosm. 2014;1:68-73.

33. Moravkova T, Filip P. The influence of emulsifier on rheological and sensory properties of cosmetic lotions. Adv Mat Sci Eng. Article ID 168503. 2013;7.

34. Medina-Torres L, Calderas F, Sanchez-Olivares G, Nuñez-Ramirez DM. Rheology of sodium polyacrylate as an emulsifier employed in cosmetic emulsions. Ind Eng Chem Res. 2014;53:18346-51.

35. Maru AD, Surawase RK, Bodhe PV. Development and evaluation of moisturizing cream containing rice bran wax. RJTCS. 2012;3(2):40-4. 